\title{
Frequency of secondary dyslipidemia in obese children
}

\author{
Ulrike Korsten-Reck' \\ Katrin Kromeyer-Hauschild ${ }^{2}$ \\ Katrin Korsten' \\ Manfred W Baumstark' \\ Hans-H Dickhuth' \\ Aloys Berg' \\ 'Department of Rehabilitative and \\ Preventive Sports Medicine, University \\ Medical Center, University of Freiburg, \\ 79106 Freiburg, Germany; ${ }^{2}$ Institute \\ of Human Genetics and Anthropology, \\ Friedrich-Schiller-University Jena, \\ 07740 Jena, Germany
}

Objective: This paper reports the frequency, type, and degree of dyslipidemia in obese children before therapeutic intervention. The relationships between lipid values and weight status, as well as lipid values and physical fitness, of these children were also investigated.

Design and methods: The initial examination of the Freiburg Intervention Trial for Obese Children (FITOC) measured the values of triglycerides (TG), total cholesterol (C), low-density lipoprotein cholesterol (LDL-C), and high-density lipoprotein cholesterol (HDL-C) in 546 obese children aged 7-12 (body mass index [BMI] $>97$ th percentile), and compared these values with those of the age- and sex-specific reference group in the Lipid Research Clinics Population Studies Data Book (LRC). Four groups were selected according to the following scheme: A, Normolipidemia; B, Hyper-LDL-cholesterolemia alone; C, Hypo-HDL-C + hypertriglyceridemia; D, Combined hyperlipidemia = Hyper-LDL-C + hypertriglyceridemia Body mass index, BMI-SDS (corrected BMI), and physical performance in watt $/ \mathrm{kg}$ body weight were measured.

Results: A total of $45.8 \%$ of the overweight children showed an abnormal lipid profile. Ten percent of the children had high LDL-C levels (group B), while 15\% had increased LDL-C and increased TG (group D) (higher prevalence in boys). In $18.9 \%$ we found increased TG, combined with decreased HDL-C values (group C).

Conclusion: Obese children are at risk of dyslipoproteinemia and related diseases. Children with the highest BMI-SDS and lowest physical fitness have the lowest HDL-C values and increased TG, indicating a higher risk for the metabolic syndrome.

Keywords: atherosclerotic risk, childhood, dyslipidemia, obesity

\section{Introduction}

Obesity is categorized as a global epidemic by the World Health Organisation (WHO). The National Health and Nutrition Examination Survey (NHANES) (1999-2000) stated that nearly $65 \%$ of American adults were overweight (BMI $>25 \mathrm{~kg} / \mathrm{m}^{2}$ ). The prevalence of obesity had increased from $23 \%$ to $31 \%$ since the previous NHANES III Survey (1988-1994). This development can also be observed in children and adolescents (Troiano et al 1995; Flegal et al 1998; Ogden et al 2002, 2003). Among children 6-15 years old, the prevalence of obesity increased 7\% (overweight 3.5\%) between 1996 and 2001 according to an English Health Survey (Joint Health Surveys Unit 2002). Cases of extreme obesity are increasingly observed in Germany and other European countries (Kromeyer-Hauschild et al 1999; Kalies et al 2002; Frye and Heinrich 2003; Ogden et al 2003). This development is alarming and predisposes this particular population to metabolic and orthopedic risk factors, as well as psychosocial disorders.

Interest in the pathogenesis of childhood atherosclerosis has intensified in the past few decades (Berenson et al 1998; Freedman et al 1999; Frontini et al 2003; Kalies et al 2002; Kromeyer-Hauschild et al 1999; Srinivasan et al 2003). The Bogalusa Heart Study demonstrated that diseased adolescents with high levels of total cholesterol (C) 
and low-density lipoprotein (LDL-C) levels already had atherosclerotic plaques (Tracy et al 1995). This constellation is caused by excessive food consumption and a decrease in physical activity (Berg et al 1994; Berg and KorstenReck 1995). An important risk factor for the development of atherosclerotic coronary heart disease is the metabolic syndrome characterized by insulin resistance, obesity, high blood pressure, and dyslipidemia (Steinberger 2003). Early childhood obesity probably plays an important role in the development of this metabolic syndrome.

The Freiburg Intervention Trial for Obese Children (FITOC) aims to reduce obesity through physical activity, diet, and behavioral education (Korsten-Reck et al 2005). This paper reports the status of frequency, type, and degree of dyslipidemia in obese children before therapeutic intervention. In addition the relationships between lipid values and weight status as well as lipid values and physical fitness of these children were investigated.

\section{Methods}

\section{Patients}

At initial examination, the children of the study were 7 to 12 years old (mean: $10.11 \pm 1.25$ years). Children participating in the program (body mass index [BMI] above the 97th percentile of the German reference group) (Kromeyer-Hauschild et al 2001) were referred by family doctors, pediatricians, or school doctors. Some were outpatients at two university clinics (Universitäts-Kinderklinik, Kinder- und Jugendpsychiatrie der Universitätsklinik). The content of the FITOC intervention program has been described previously (Korsten-Reck et al 2005). We summarize the lipid profile values of the pre-start examination of all participants taken over 9 years. We compared the values of these children $(n=546)$ with the age- and sex-specific reference group of the Lipid Research Clinics Population Studies Data Book (LRC). These LRC data are given in Table 1 (US Dept of Health and Human Services 1980). No guideline values for childhood lipid values appear in German publications. The age- and sex-specific 90th percentile $\left(\mathrm{P}_{90}\right)$ for triglycerides (TG) as well as for LDL-cholesterol values was set as the upper limit and the age- and sex-specific 10th percentile $\left(\mathrm{P}_{10}\right)$ for high-density lipoprotein cholesterol (HDL-C) was defined as the lower limit. Four groups were selected according to the following scheme: A, Normolipidemia [triglycerides (TG) < age- and sex-specific $\mathrm{P}_{90}$, HDH-C (HDL-C) $>$ ageand sex-specific $\mathrm{P}_{10}$ ]; B: Hyper-LDL-cholesterolemia alone [LDL-C $>$ age- and sex-specific $\mathrm{P}_{90}$, TG $<$ age- and sex-specific $\mathrm{P}_{90}$ ]; C: Hypo-HDL-C + Hypertriglyceridemia
Table I LRC-data for LDL- and HDL-cholesterol, and triglycerides 90 th percentile by age, gender, and race

\begin{tabular}{llllll}
\hline & \multicolumn{2}{l}{ White boys } & & \multicolumn{2}{l}{ White girls } \\
\cline { 2 - 3 } \cline { 6 - 7 } Age & $5-9$ & $10-14$ & & $5-9$ & $10-14$ \\
LDL-cholesterol & 117 & 122 & & 125 & 126 \\
HDL-cholesterol & 42 & 40 & & 38 & 40 \\
Triglycerides & 85 & 102 & & 90 & 114 \\
\hline
\end{tabular}

Abbreviations: LDL, low-density lipoprotein, 90th percentile; LRC, The Lipid Research Clinics' Population Studies Data Book, Volume I; Triglycerides, 90th percentile; HDL, high-density lipoprotein, I0th percentile.

[HDL-C $<$ age- and sex-specific $\mathrm{P}_{10}, \mathrm{TG}>$ age- and sex-specific $\mathrm{P}_{90}$ ]; D: Combined hyperlipidemia $=$ Hyper-LDL$\mathrm{C}+$ Hypertriglyceridemia [LDL-C $>$ age- and sex-specific $\mathrm{P}_{90}, \mathrm{TG}>$ age- and sex-specific $\left.\mathrm{P}_{90}\right]$. As well as total cholesterol, TG, HDL-C, and LDL-C, BMI, BMI-standard deviation score-values (BMI-SDS) (corrected BMI), and physical performance in watt/kg body weight were measured.

\section{Methods}

The biochemical methods were identical during the whole investigation. Total cholesterol was assayed using enzymatic colorimetric tests (cholesterol CHOD-PAP-method); LDL-cholesterol and HDL-cholesterol were measured using lipoprotein electrophoresis (Helena REP Diagnostic, Greiner Bio Chemica). Our laboratory takes part in an external certification program (DIN EN ISO 9001).

BMI was used as a basis for weight status. To correct for age and sex, individual BMI-values were converted to Z-scores (SDS values). Calculation of SDS values was based on the national reference data available for German children (Kromeyer-Hauschild et al 2001). These references were derived using Cole's LMS method (Cole and Green 1992), which allows BMI in individual subjects to convert to SD scores as follows:

$$
\mathrm{SDS}=\left[(\mathrm{X} / \mathrm{M}(\mathrm{t}))^{\mathrm{L}(\mathrm{t})}-1\right] / \mathrm{L}(\mathrm{t}) \mathrm{S}(\mathrm{t})
$$

where $\mathrm{X}=$ individual BMI-value, $\mathrm{L}=$ Box-Cox power, $\mathrm{M}=$ Median, and $\mathrm{S}=$ coefficient of variation for individual age $(\mathrm{t})$ and sex from the reference group. Results are indicated as BMI-SDS values.

Physical performance as watt/kg bodyweight was gauged with a standard bicycle ergometer (Lode, Groningen, NL) using a typical test protocol starting at 25 or 50 watts and increasing the work load by 25 watts every three minutes until exhaustion.

The sex-specific number of children in the above mentioned age- and sex-specific 90th percentiles for TG and LDL as well below the 10th percentile for HDL of the 
reference group was calculated. The children were also classified in the above mentioned lipid groups. Gender differences between the frequencies in the four lipid groups were tested by using chi-square test for categorical variables. Analyses of variance (ANOVA) with Tamhane T2 post hoc contrasts were used to compare the differences in BMI-SDS and fitness (watt $/ \mathrm{kg}$ bodyweight) between the lipid-groups. Normal distribution of BMI-SDS $(\mathrm{p}=0.945)$ and watt $/ \mathrm{kg}$ bodyweight $(\mathrm{p}=0.184)$ were examined by KolmogorovSmirnoff test. Statistical inferences were drawn at a significance level of 5\%. All statistical analyses were performed using SPSS 11.5.2.1 (SPSS Inc., Chicago, IL). The study was approved by the University of Freiburg Ethics Committee.

\section{Results}

The characteristics of the patients in this study are summarized in Table 2. The BMI and BMI-SDS of the boys were significantly higher than those of the girls.

About $40 \%$ of the children have total cholesterol values above the age- and sex-specific 90th percentile, and about $30 \%$ above the 90 th percentile for LDL-C and TG (Table 3 ). In contrast more than $20 \%$ of the children showed a HDL-C value below the age- and sex-specific 10th percentile. There are more boys with LDL-C values above the 90th percentile than girls (Table 3). In both sexes, a higher degree of lipid abnormalities was found in our overweight children compared with the LRC data (Figure 1). A large number of children also have combined lipid disturbances. Only half the children showed a normal lipid profile (group A). We found significant sex differences among the four groups (Table 4). About $12 \%$ of the children had only high LDL-C level (group B), while 15\% had increased LDL-C and increased TG (higher prevalence in boys) (group D) (Table 4). In 18.9\% we found increased TG combined with decreased HDL-C values (group C). This combination was more common in girls ( $23 \%$ versus $14 \%)$.
Table 2 Characteristics of the obese children examined

\begin{tabular}{lllll}
\hline & & N & Mean & SD \\
\hline Age $(\mathrm{yrs})$ & Boys & 249 & 10.120 & 1.241 \\
& Girls & 297 & 10.104 & 1.255 \\
& Total & 546 & 10.112 & 1.247 \\
BMI $\left(\mathrm{kg} / \mathrm{m}^{2}\right)$ & Boys & 249 & 27. I $^{\#}$ & 3.6 \\
& Girls & 297 & $26.2^{\#}$ & 3.4 \\
& Total & 546 & 26.6 & 3.5 \\
BMI-SDS & Boys & 249 & $2.37^{*}$ & 0.45 \\
& Girls & 297 & $2.26^{*}$ & 0.49 \\
& Total & 546 & 2.31 & 0.47 \\
WATT/KG & Boys & 178 & 1.9 & 0.5 \\
& Girls & 214 & 1.8 & 0.4 \\
& Total & 392 & 1.8 & 0.4 \\
\hline
\end{tabular}

Notes: Significant differences between sexes; ${ }^{*} \mathrm{p}=0.00 \mathrm{I}$; U-Test $* \mathrm{p}=0.005$; T-Test. Abbrevations: BMI, body mass index; BMI-SDS, body mass index standard deviation score-values.

There is a significant variation in BMI-SDS and physical fitness between the four lipid groups (Tables 5 and 6). Children with the highest BMI-SDS and the lowest physical fitness have the lowest HDL-C values and highest TG (group C) indicating a higher risk for metabolic syndrome. Group B shows no significant differences in the level of BMI-SDS and physical fitness compared with group A.

\section{Discussion}

The purpose of this study was to show the lipid values of a cohort of obese children ( $>97$ th percentile) before starting an intervention program. Obesity in childhood predisposes for metabolic syndrome with high blood pressure, changes in glucose metabolism, and dyslipidemia in adulthood (Hubert et al 1983; Kaufman 2002; McGill et al 2002; Kavey et al 2003). The relationship of obesity to cardiovascular risk factors is not only defined by the level of obesity but also by the distribution of fat. Research has shown

Table 3 Frequencies (\%) of children with values for $\mathrm{CH}$, LDL-C, and TG above $\mathrm{P}_{90}$ and for HDL-C below $\mathrm{P}_{10}$

\begin{tabular}{|c|c|c|c|c|c|c|c|}
\hline & \multirow{2}{*}{$\begin{array}{l}\begin{array}{l}\text { Number } \\
\text { of children }\end{array} \\
\text { (boys/girls) }\end{array}$} & \multicolumn{2}{|c|}{ Boys } & \multicolumn{2}{|c|}{ Girls } & \multicolumn{2}{|c|}{ Total } \\
\hline & & $\mathbf{n}$ & $\%(95 \% \mathrm{Cl})$ & $\mathbf{n}$ & $\%(95 \% \mathrm{Cl})$ & $\mathbf{n}$ & (\%) $(95 \% \mathrm{CI})$ \\
\hline $\mathrm{CH}>\mathrm{P}_{90}$ & $546(249 / 297)$ & 102 & $41.0(34.8-47.4)$ & 108 & $36.4(30.9-42.1)$ & 210 & $38.5(34.4-42.7)$ \\
\hline LDL-C $>P_{90}$ & $54 I(248 / 293)$ & 80 & $32.3(26.5-38.5)$ & 67 & 22.9 (8.2-28.I) & 147 & $27.2(23.5-3||)$. \\
\hline $\mathrm{TG}>\mathrm{P}_{90}$ & $545(248 / 297)$ & 82 & $33.1(27.2-39.3)$ & 103 & $34.7(29.3-40.4)$ & 185 & $33.9(30.0-38.1)$ \\
\hline HDL-C $<\mathrm{P}_{10}$ & $545(249 / 296)$ & 50 & $20.1(I 5.3-25.6)$ & 74 & $25.0(20.1-30.3)$ & 124 & $22.8(19.3-26.5)$ \\
\hline
\end{tabular}

Note: $95 \% \mathrm{Cl}, 95 \%$ exact confidence limits.

Abbreviations: $\mathrm{Cl}$, confidence interval; $\mathrm{CH}$, cholesterol; HDL-C, high-density lipoprotein-cholesterol; LDL-C, low-density lipoprotein-cholesterol; $\mathrm{P}_{10}$, I0th percentile; $\mathrm{P}_{90}$, 90th percentile; TG, triglycerides. 


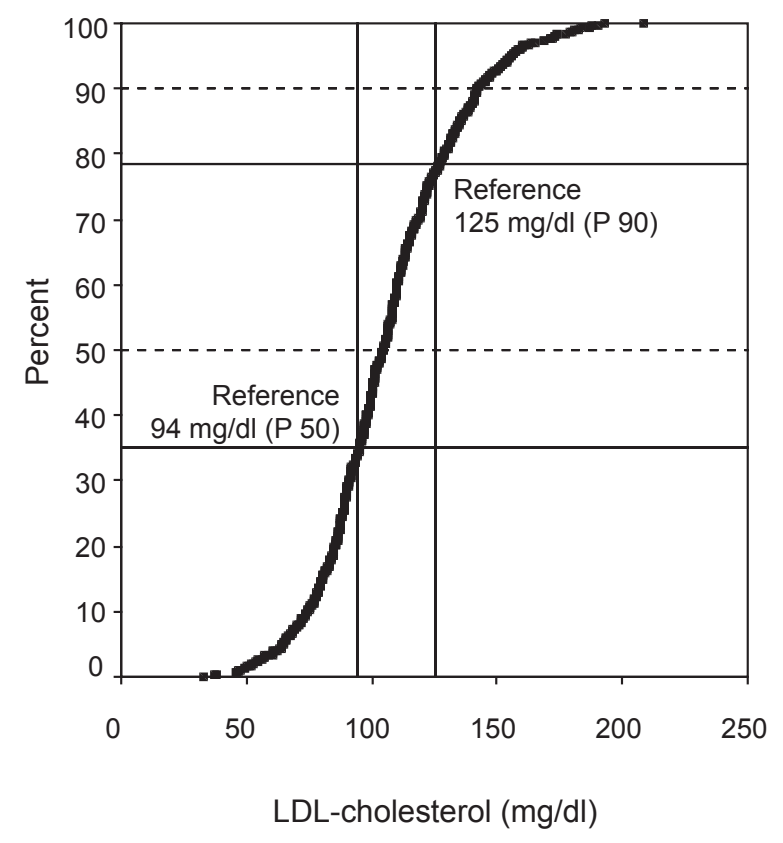

Figure I Distribution of the individual LDL-C of FITOC Children compared with the LRC Study.

Abbreviations: FITOC, freiburg intervention trial for obese children; LDL-C, low-density lipoprotein cholesterol; LRC, lipid research clinics population studies data book.

that children with a large visceral component compared to peripheral fat can develop metabolic syndrome just like adults (Moreno et al 2002). Obese children develop not only insulin resistance but dyslipidemia as result of obesity and the prevalence is higher than seen among normal weight children (Freedman et al 1999). One study by Berenson demonstrates that obesity is not only associated with dyslipidemia but accelerates the atherosclerotic process in adolescents and young adults (Berenson et al 1998). Recently published pediatric studies have focused on atherosclerosis as a process beginning in early childhood and related to obesity. Framingham Study data showed an increased incidence of cardiovascular events with increasing bodyweight, independent of gender.

Considering these results, lipid value screening appears to be helpful at the beginning of an intervention program for obese children. However, medical treatment of dyslipidemia in childhood is controversial and is so far only indicated for familial heterozygotic hypercholesterolemia (Stefanutti et al 1999; Stein et al 1999). In contrast to treatment with drugs, lifestyle intervention has no inherent risk.

We compared pre-start FITOC lipid data from obese children with the LRC data because there are only a few comparable studies in the literature. Although the LRC data were collected in 1980, the 1998 American Academy of Pediatrics (AAP) recommendations set the same limits for LDL-C. These recommendations define lower than $110 \mathrm{mg} / \mathrm{dL}$ as a normal value, $130 \mathrm{mg} / \mathrm{dL}$ as borderline high, and more than $130 \mathrm{mg} / \mathrm{dl}$ as a high value (AAP 1998).

Comparing the distribution of the lipid values of FITOC children with levels in the LRC studies, only $54.2 \%$ of the FITOC children showed a normal lipid profile (group A), whereas about $10 \%$ had a hyper-LDL-C alone (group B) and about 20\% showed the "atherogenic" lipid profile with hypo-HDL-C and hyper-trigliceridemia (group C) (Steinberger 2003).

Our results confirm the findings of other studies which show a higher frequency of dyslipidemia in obese children (Freedman et al 1999; Dirisamer and Widhalm 2002).

The Bogalusa Heart Study reported the probability of overweight children developing high TG, and total- and LDL-C levels 2.4-7.1 times greater than in normal-weight children. The increase in individual insulin resistance may explain a significant part of the variance in the TG, LDL-C, and HDL-C values (Freedman et al 1999). In Germany

Table 4 Distribution of the children in the four lipid profile groups

\begin{tabular}{|c|c|c|c|c|c|c|c|}
\hline & \multirow[t]{2}{*}{ Group } & \multicolumn{2}{|c|}{ Boys } & \multicolumn{2}{|c|}{ Girls } & \multicolumn{2}{|c|}{ Total } \\
\hline & & $\mathbf{n}$ & $\%(95 \% \mathrm{Cl})$ & $\mathbf{n}$ & $\%(95 \% \mathrm{Cl})$ & $\mathbf{n}$ & $\%(95 \% \mathrm{Cl})$ \\
\hline A & $\begin{array}{l}\text { Normolipidemia } \\
\left(\mathrm{HDL}>\mathrm{P}_{10}+\mathrm{TG}<\mathrm{P}_{90}\right)\end{array}$ & 134 & $53.8(47.4-60.1)$ & 162 & $54.5(48.7-60.3)$ & 296 & $54.2(49.9-58.5)$ \\
\hline B & $\begin{array}{l}\text { Hyper-LDL-C alone } \\
\left(\mathrm{LDL}>\mathrm{P}_{90}+\mathrm{TG}<\mathrm{P}_{90}\right)\end{array}$ & 32 & $12.9(9.0-17.7)$ & 32 & $10.8(7.5-14.9)$ & 64 & $11.7(9.2-14.7)$ \\
\hline C & $\begin{array}{l}\text { Hypo-HDL-C + Hypertriglyceridemia } \\
\left(\mathrm{HDL}<\mathrm{P}_{10}+\mathrm{TG}>\mathrm{P}_{90}\right)\end{array}$ & 35 & I4.I (10.0-19.0) & 68 & $22.9(18.2-28.1)$ & 103 & $18.9(15.7-22.4)$ \\
\hline D & $\begin{array}{l}\text { Hyper-LDL-C + Hypertriglyceridemia } \\
\left(\mathrm{LDL}>\mathrm{P}_{90}+\mathrm{TG}>\mathrm{P}_{90}\right)\end{array}$ & 48 & $19.3(14.6-24.7)$ & 35 & II.8 (8.4-I6.0) & 83 & $15.2(12.3-18.5)$ \\
\hline
\end{tabular}

Notes: $95 \% \mathrm{Cl}, 95 \%$ exact confidence limits.

Abbreviations: $\mathrm{Cl}$, confidence interval; $\mathrm{HDL}-\mathrm{C}$, high-density lipoprotein-cholesterol; LDL-C, low-density lipoprotein-cholesterol; $\mathrm{P}_{10}$, 10 th percentile; $\mathrm{P}_{90}$, 90 th percentile; TG, triglyceride. 
Table 5 Mean BMI-SDS-values in the different lipid profile groups

\begin{tabular}{|c|c|c|c|c|c|c|c|c|c|c|}
\hline & \multirow[t]{2}{*}{ Group* } & \multicolumn{3}{|c|}{ Boys } & \multicolumn{3}{|c|}{ Girls } & \multicolumn{3}{|c|}{ Total } \\
\hline & & n & Mean & SD & $n$ & Mean & SD & n & Mean & SD \\
\hline$A^{1,2}$ & $\begin{array}{l}\text { Normolipidemia } \\
\left(\mathrm{HDL}>\mathrm{P}_{10}+\mathrm{TG}<\mathrm{P}_{90}\right)\end{array}$ & 134 & 2.3 & 0.4 & 162 & 2.1 & 0.5 & 296 & 2.2 & 0.4 \\
\hline $\mathrm{B}^{3}$ & $\begin{array}{l}\text { Hyper-LDL-C alone } \\
\left(\mathrm{LDL}>\mathrm{P}_{90}+\mathrm{TG}<\mathrm{P}_{90}\right)\end{array}$ & 32 & 2.4 & 0.6 & 32 & 2.1 & 0.5 & 64 & 2.3 & 0.5 \\
\hline$C^{1,3}$ & $\begin{array}{l}\text { Hypo-HDL-C + Hypertriglyceridemia } \\
\left(\mathrm{HDL}<\mathrm{P}_{10}+\mathrm{TG}>\mathrm{P}_{90}\right)\end{array}$ & 35 & 2.5 & 0.5 & 68 & 2.5 & 0.5 & 103 & 2.5 & 0.5 \\
\hline $\mathrm{D}^{2}$ & $\begin{array}{l}\text { Hyper-LDL-C + Hypertrigliceridemia } \\
\left(\mathrm{LDL}>\mathrm{P}_{90}+\mathrm{TG}>\mathrm{P}_{90}\right)\end{array}$ & 48 & 2.4 & 0.4 & 35 & 2.3 & 0.4 & 83 & 2.4 & 0.4 \\
\hline
\end{tabular}

Notes: *Significant differences between the groups (ANOVA; $p<0.00 \mathrm{I}$ ); 'Significant differences between group A and $\mathrm{C}$ (Tamhane T2; $\mathrm{p}<0.05$ ); ${ }^{2}$ Significant differences between group A and D (Tamhane T2; $<<0.05$ ); ${ }^{3}$ Significant differences between group B and C (Tamhane T2; $\left.<<0.05\right)$.

Abbreviations: BMI-SDS, MI-SDS, body mass index standard deviation score-values; Cl, confidence interval; HDL-C, high-density lipoprotein-cholesterol; LDL-C, low-density lipoprotein-cholesterol; $P_{10}$, I0th percentile; $P_{90}$, 90th percentile; $T G$, triglycerides.

we have few representative population-based samples of childhood lipid values and cardiovascular risk factors. One other study presents cardiovascular risk factors of a large population, but combined-lipid-cluster-groups and correlations to physical-performance data as in our study are not mentioned (Reinehr 2005). Moreover, we found significantly higher total-C and LDL-C values in boys as well as TG in our total cohort compared with an Austrian control group (Dirisamer and Widhalm 2002).

The mechanism of change in the lipid profile could be: hyperinsulinemia causes hepatic VLDL-synthesis and leads to increased TG- and LDL-C-levels. The lack of the effect of insulin on lipoproteinlipase in peripheral tissues could then result in an increase in TG and LDL-C.

In addition, hyperinsulinemia in children leads to further alterations in fatty acid oxidation and concentrations (Sinaiko et al 2002). Other metabolic factors, such as an increase in levels of apolipoprotein B, homocysteine, and C-reactive protein are risk factors for atherosclerotic coronary heart disease (Sinha et al 2002; Halle et al 2004).

There is no doubt that the atherosclerotic process in adults seems to originate in childhood obesity with dyslipidemia, and must be treated in a timely fashion. In this age group, nondrug therapy is possible because unhealthy eating and behavioral habits are not yet fully established. New eating, behavioral, and activity patterns can be formed (Epstein et al 2000).

In conclusion, obesity in childhood predisposes for coronary heart disease in adults. In view of the socioeconomic significance of the increasing prevalence of childhood obesity, early screening is indispensable. Particular attention should be focused on the timely prevention of childhood obesity and corresponding dyslipidemia. Risk groups should be identified and treated accordingly. Longitudinal data of dyslipidemia in obese children are important for the prevention of metabolic syndrome.

Table 6 Mean physical fitness in the different lipid profile groups

\begin{tabular}{|c|c|c|c|c|c|c|c|c|c|c|}
\hline & \multirow[t]{2}{*}{ Group* } & \multicolumn{3}{|c|}{ Boys } & \multicolumn{3}{|c|}{ Girls } & \multicolumn{3}{|c|}{ Total } \\
\hline & & $\mathbf{n}$ & Mean & SD & n & Mean & SD & $\mathbf{n}$ & Mean & SD \\
\hline$A^{\prime}$ & $\begin{array}{l}\text { Normolipidemia } \\
\left(\mathrm{HDL}>\mathrm{P}_{10}+\mathrm{TG}<\mathrm{P}_{90}\right)\end{array}$ & 104 & 1.9 & 0.5 & 114 & 1.8 & 0.4 & 218 & 1.9 & 0.4 \\
\hline$B^{3}$ & $\begin{array}{l}\text { Hyper-LDL-C alone } \\
\left(\mathrm{LDL}>\mathrm{P}_{90}+\mathrm{TG}<\mathrm{P}_{90}\right)\end{array}$ & 16 & 2.0 & 0.4 & 25 & 1.9 & 0.4 & $4 I$ & 1.9 & 0.4 \\
\hline $\mathrm{C}^{1,3}$ & $\begin{array}{l}\text { Hypo-HDL-C + Hypertriglyceridemia } \\
\left(\mathrm{HDL}<\mathrm{P}_{10}+\mathrm{TG}>\mathrm{P}_{90}\right)\end{array}$ & 25 & 1.7 & 0.5 & 50 & 1.7 & 0.3 & 75 & 1.7 & 0.4 \\
\hline D & $\begin{array}{l}\text { Hyper-LDL-C + Hypertriglyceridemia } \\
\left(\mathrm{LDL}>\mathrm{P}_{90}+\mathrm{TG}>\mathrm{P}_{90}\right)\end{array}$ & 33 & 1.8 & 0.4 & 25 & 1.8 & 0.4 & 58 & 1.8 & 0.4 \\
\hline
\end{tabular}

Notes: *Significant differences between the groups (ANOVA; $\mathrm{p}=0.00 \mathrm{I}$ ); 'Significant differences between group A and $\mathrm{C}$ (Tamhane T2; $\mathrm{P}<0.05$ ); ${ }^{3}$ Significant differences between group $B$ and $C$ (Tamhane T2; $\mathrm{p}<0.05)$.

Abbreviations: HDL-C, high-density lipoprotein-cholesterol; LDL-C, low-density lipoprotein-cholesterol; $\mathrm{P}_{10}$, 10th percentile; $\mathrm{P}_{90}$, 90th percentile; $\mathrm{SD}$, standard deviation; TG, triglycerides. 


\section{Acknowledgments}

U. Korsten-Reck designed and coordinated the intervention program. A. Berg and H.-H. Dickhuth drafted the paper. K. Korsten assessed the patients and data. K. KromeyerHauschild and M.W. Baumstark analysed and interpreted data and provided statistical support. All authors critically reviewed this manuscript and approved the final version. The authors report no conflicts of interest in this work.

\section{References}

[AAP] American Academy of Pediatrics, Committee on Nutrition. Cholesterol in childhood. 1998. Cholesterol in childhood. Pediatrics, 101:141-7.

Berenson GS, Srinivasan SR, Bao W, et al. 1998. Association between multiple cardiovascular risk factors and atherosclerosis in children and young adults. The Bogalusa Heart Study. N Engl J Med, 338:1650-6.

Berg A, Halle M, Bauer S, et al. 1994. Physical activity and eating behavior: strategies for improving the serum lipid profile of children and adolescents. Wien Med Wochenschr, 144:138-44.

Berg A, Korsten-Reck U. 1995. [Strategien zur Verbesserung des Aktivitäts- und Ernährungsverhaltens bei Kindern und Jugendlichen.] Der Lipidreport, 4:15-22.

Cole TJ, Green PJ. 1992. Smoothing reference centile curves: the LMS method and penalized likelihood. Stat Med, 11:1305-19.

Dirisamer A, Widhalm K. 2002. Lipoprotein(a) as a potent risk indicator for early cardiovascular disease. Acta Paediatr, 91:1313-17.

Epstein LH, Paluch RA, Gordy CC, et al. 2000. Decreasing sedentary behaviors in treating pediatric obesity. Arch Pediatr Adolesc Med, 154:220-6.

Flegal KM, Carroll MD, Kuczmarski RJ, et al. 1998. Overweight and obesity in the United States: prevalence and trends, 1960-1994. Int J Obes Relat Metab Disord, 22:39-47.

Freedman DS, Dietz WH, Srinivasan SR, et al. 1999. The relation of overweight to cardiovascular risk factors among children and adolescents: the Bogalusa Heart Study. Pediatrics, 103:1175-82.

Frontini MG, Srinivasan SR, Berenson GS. 2003. Longitudinal changes in risk variables underlying metabolic Syndrome $\mathrm{X}$ from childhood to young adulthood in female subjects with a history of early menarche: the Bogalusa Heart Study. Int J Obes Relat Metab Disord, 27:1398-404.

Frye C, Heinrich J. 2003. Trends and predictors of overweight and obesity in East German children. Int J Obes Relat Metab Disord, 27:963-9.

Halle M, Korsten-Reck U, Wolfarth B, et al. 2004. Low-grade systemic inflammation in overweight children: impact of physical fitness. Exerc Immunol Rev, 10:66-74.

Hubert HB, Feinleib M, McNamara PM, et al. 1983. Obesity as an independent risk factor for cardiovascular disease: a 26-year followup of participants in the Framingham Heart Study. Circulation, 67:968-77.

Kalies H, Lenz J, von Kries R. 2002. Prevalence of overweight and obesity and trends in body mass index in German pre-school children, 1982-1997. Int J Obes Relat Metab Disord, 26:1211-7.

Kaufman FR. 2002. Type 2 diabetes mellitus in children and youth: a new epidemic. J Pediatr Endocrinol Metab, 15(Suppl 2):737-44.
Kavey RE, Daniels SR, Lauer RM, et al. 2003. American Heart Association guidelines for primary prevention of atherosclerotic cardiovascular disease beginning in childhood. Circulation, 107:1562-6.

Korsten-Reck U, Kromeyer-Hauschild K, Wolfarth B, et al. 2005. Freiburg Intervention Trial for Obese Children (FITOC): results of a clinical observation study. Int J Obes Relat Metab Disord, 29:356-61.

Kromeyer-Hauschild K, Wabitsch M, Kunze D. 2001. [Perzentile für den Body-Mass-Index für das Kinder- und Jugendalter unter Heranziehung verschiedener deutscher Stichproben.] Monatsschr Kinderheilkd, 149:807-18.

Kromeyer-Hauschild K, Zellner K, Jaeger U, et al. 1999. Prevalence of overweight and obesity among school children in Jena (Germany). Int J Obes Relat Metab Disord, 23:1143-50.

McGill HC Jr, McMahan CA, Herderick EE, et al. 2002. Obesity accelerates the progression of coronary atherosclerosis in young men. Circulation, 105:2712-8.

Moreno LA, Pineda I, Rodriguez G, et al. 2002. Waist circumference for the screening of the metabolic syndrome in children. Acta Paediatr, 91:1307-12.

Ogden CL, Carroll MD, Flegal KM. 2003. Epidemiologic trends in overweight and obesity. Endocrinol Metab Clin North Am, 32:741-60, vii.

Ogden CL, Flegal KM, Carroll MD, et al. 2002. Prevalence and trends in overweight among US children and adolescents, 1999-2000. JAMA, 288:1728-32.

Reinehr T. 2005. Cardiovascular risk factors in overweight German children and adolescents: relation to gender, age and degree of overweight. Nutr Metab Cardiovasc Dis, 15:181-7.

Sinaiko AR, Steinberger J, Moran A, et al. 2002. Relation of insulin resistance to blood pressure in childhood. J Hypertens, 20:509-17.

Sinha R, Fisch G, Teague B, et al. 2002. Prevalence of impaired glucose tolerance among children and adolescents with marked obesity. $N$ Engl J Med, 346:802-10.

Srinivasan SR, Frontini MG, Berenson GS. 2003. Longitudinal changes in risk variables of insulin resistance syndrome from childhood to young adulthood in offspring of parents with type 2 diabetes: the Bogalusa Heart Study. Metabolism, 52:443-50.

Stefanutti C, Lucani G, Vivenzio A, et al. 1999. Diet only and diet plus simvastatin in the treatment of heterozygous familial hypercholesterolemia in childhood. Drugs Exp Clin Res, 25:23-8.

Stein EA, Illingworth DR, Kwiterovich PO Jr, et al. 1999. Efficacy and safety of lovastatin in adolescent males with heterozygous familial hypercholesterolemia: a randomized controlled trial. JAMA, 281:137-44.

Steinberger J. 2003 .Diagnosis of the metabolic syndrome in children. Curr Opin Lipidol, 14:555-9.

Tracy RE, Newman WP III, Wattigney WA, et al. 1995. Risk factors and atherosclerosis in youth autopsy findings of the Bogalusa Heart Study. Am J Med Sci, 310(Suppl 1):S37-S41.

Troiano RP, Flegal KM, Kuczmarski RJ, et al. 1995. Overweight prevalence and trends for children and adolescents. The National Health and Nutrition Examination Surveys, 1963 to 1991. Arch Pediatr Adolesc Med, 149:1085-91.

US Dept of Health and Human Services. 1980. The Lipid Research Clinics' Population Studies Data Book. Washington, DC: National Institutes of Health. 